\title{
The role of pediatricians as key stakeholders in influencing immunization policy decisions for the introduction of meningitis B vaccine in Canada: The Ontario perspective
}

\author{
Hirotaka Yamashiro MD FRCP C FAAP, Nora Cutcliffe MSc PhD, Simon Dobson MD FRCP C, \\ David Fisman MD MPH FRCP C, Ronald Gold MD MPH
}

H Yamashiro, N Cutcliffe, S Dobson, D Fisman, R Gold. The role of pediatricians as key stakeholders in influencing immunization policy decisions for the introduction of meningitis $B$ vaccine in Canada: The Ontario perspective. Can J Infect Dis Med Microbiol 2015;26(4):183-190.

As key stakeholders in immunization policy decisions, the Pediatricians of Ontario held an accredited conference on January 18, 2014, to discuss prevention of invasive meningococcal disease. Five key recommendations were put forth regarding immunization strategies to protect children from meningococcal serogroup $\mathrm{B}$ disease. The recently approved four-component meningococcal B (4CMenB) vaccine should be recommended and funded as part of Ontario's routine immunization schedule and should also be mandated for school attendance. Public funding for $4 \mathrm{CMenB}$ immunization is justified based on current MenB epidemiology, vaccine coverage, cost effectiveness and acceptability, as well as legal, political and ethical considerations related to $4 \mathrm{CMenB}$ immunization, particularly because routine recommendations and funding are currently in place for vaccination against meningococcal serogroups that cause significantly less disease in Canada than MenB. Broadly, the goals are to assist individual practitioners in advocating the benefits of $4 \mathrm{CMenB}$ vaccination to parents, and to counterbalance recommendations from the National Advisory Committee on Immunization and the Canadian Paediatric Society.

Key Words: 4CMenB vaccine; Immunization policy; Invasive meningococcal disease (IMD); Pediatricians; Preventive care; Serogroup B
Le rôle des pédiatres comme principaux intervenants pour influencer les décisions relatives aux politiques sur l'introduction du vaccin contre la méningite du sérogroupe $B$ au Canada : le point de vue de l'Ontario

À titre de principaux intervenants à l'égard des décisions relatives aux politiques de vaccination, les Pediatricians of Ontario a organisé un colloque agréé le 18 janvier 2014 pour discuter de la prévention des méningococcies invasives. Il a formulé cing grandes recommandations sur les stratégies de vaccination pour protéger les enfants des méningococcies du sérogroupe $B$ (MenB). Le vaccin contre le méningocoque de sérogroupe B (4CMenB) qui a récemment été approuvé devrait être recommandé et financé dans le cadre du calendrier de vaccination systématique de l'Ontario et être exigé pour pouvoir fréquenter l'école. Le financement public du vaccin $4 \mathrm{CMenB}$ est justifié compte tenu de l'épidémiologie actuelle de la MenB, de la couverture vaccinale, de l'efficience et de l'acceptabilité, de même que des considérations juridiques, politiques et éthiques liées au vaccin $4 \mathrm{CMenB}$, particulièrement parce que les recommandations et le financement de la vaccination systématique sont déjà en place au Canada contre des sérogroupes du méningocoque qui sont beaucoup moins graves que le MenB. En général, le regroupement vise ainsi à aider les praticiens à préconiser les avantages du vaccin $4 \mathrm{CMenB}$ auprès des parents et à compenser les recommandations du Comité consultatif national d'immunisation et de la Société canadienne de pédiatrie.

\begin{abstract}
In Canada, the list of 'licensed but unfunded' vaccines, which are approved by Health Canada but unfunded by provincial health authorities, continues to expand. New professional guidance is required to clarify the optimal use and benefits of such vaccines, including educational campaigns developed according to public health departments, physicians, pharmacists, manufacturers and professional associations (1). Professional medical associations play a particularly important role in advocating for licensed vaccines (both funded and unfunded), not only because the public values expert medical advice that is independent of government or industry, but because individuals typically trust physicians and related professional bodies (2).
\end{abstract}

UNIQUE CONTRIBUTION OF THE PEDIATRICIANS OF ONTARIO IN SHAPING IMMUNIZATION POLICY In Ontario, the Pediatrics Section of the Ontario Medical Association and the Pediatricians Alliance of Ontario act jointly as the 'Pediatricians of Ontario' to represent Ontario's 1200 pediatricians, and to advocate for the delivery of excellent children's health care $(3,4)$. As a bold step toward advancing childhood immunization, the Pediatricians of Ontario held a conference, accredited by the Maintenance of Certification program of the Royal College of Physicians and Surgeons of Canada, on January 18, 2014, in Toronto, to discuss the prevention of invasive meningococcal disease (IMD) in

Pediatrics Section, Ontario Medical Association (PSOMA) and Pediatricians Alliance of Ontario (PAO); 'Pediatricians of Ontario' Correspondence: Dr Ronald Gold, University of Toronto, 46 Waverley Road, Toronto, Ontario M4L 3T1.

Telephone 416-691-4852, e-mail rongold16@gmail.com 


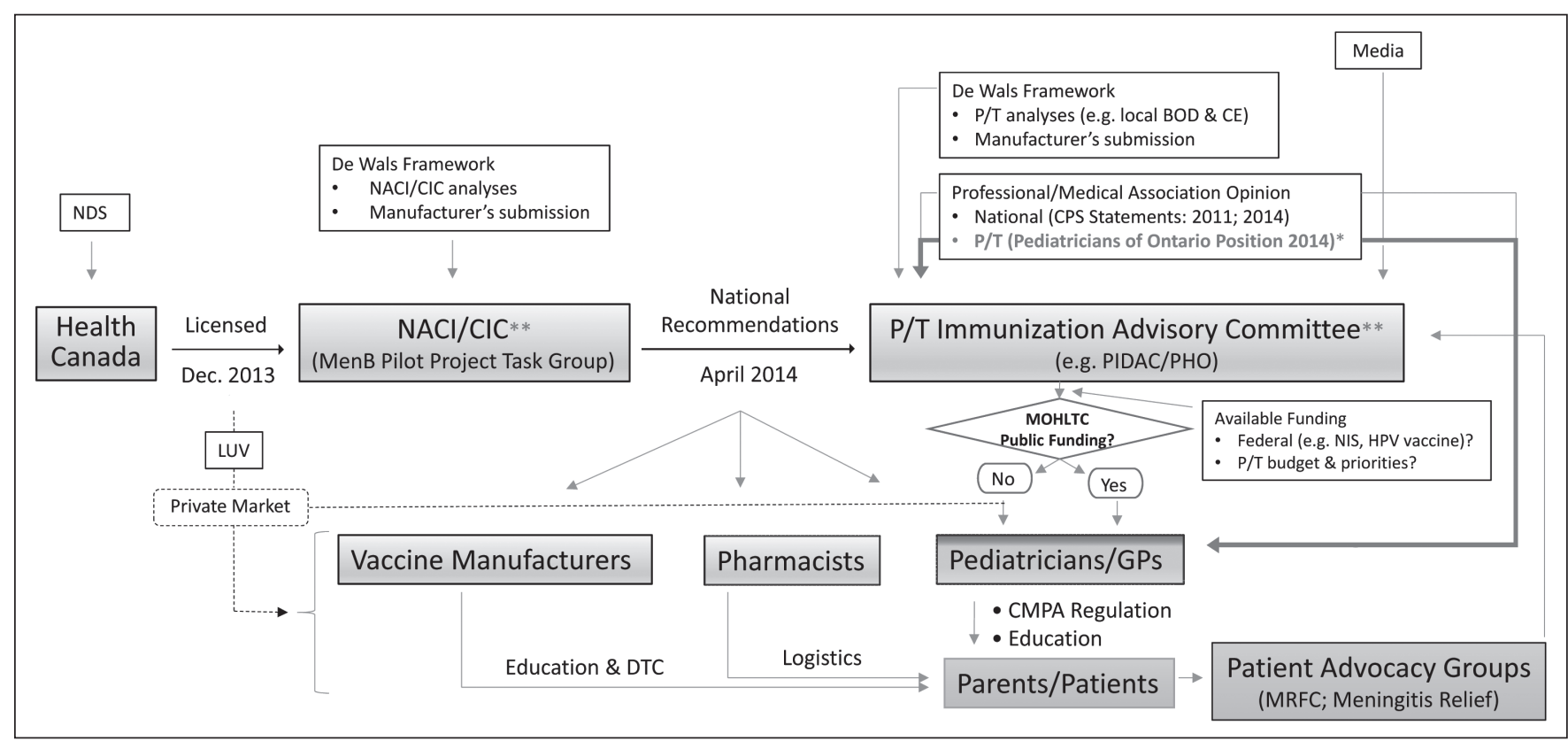

Figure 1) Role of the Pediatricians of Ontario in influencing immunization policy and funding decisions (eg, four-component meningococcal B vaccine). *Pediatricians of Ontario contribute a critical voice in informing provincial immunization policy decisions (and informing GPs) regarding 4CMenB vaccination; **Pediatricians of Ontario also seeking increased opportunities for direct contribution as key stakeholders on national and jurisdictional immunization advisory committees. BOD Burden of disease; CE Cost effectiveness; CIC Canadian Immunization Committee; CMPA Canadian Medical Protective Association; CPS Canadian Paediatric Society; Dec December; DTC Direct to consumer; GPs General practitioners; HPV Human papillomavirus; LUV Licensed but unfunded; MOHLTC Ministry of Health and Long-Term Care (Ontario); MRFC Meningitis Research Foundation of Canada; NACI National Advisory Committee on Immunization; NDS New drug submission; NIS National Immunization Strategy; PHO Public Health Ontario; PIDAC Provincial Infectious Disease Advisory Committee; P/T Provincial/territorial

Ontario. This meeting included participation of 41 members (19 onsite, 22 by live broadcast webinar) and is archived at www.pedsontario.com, Members Section. Our goal is to ensure that Ontario pediatricians play an integral role as key stakeholders in influencing immunization policy and funding decisions, particularly related to the introduction of the newly approved four-component meningococcal B (4CMenB) vaccine (5).

The Pediatricians of Ontario position is intended to provide medical opinion, in addition to statements issued by the National Advisory Committee on Immunization (NACI) $(6,7)$ and/or Canadian Immunization Committee, and the Canadian Paediatric Society $(8,9)$. In advocating the benefits of $4 \mathrm{CMenB}$ immunization to public health policy makers and to Ontario pediatricians in frontline practice, the present position paper should broaden the use of the $4 \mathrm{CMenB}$ vaccine (Figure 1; bold arrows).

\section{MENINGITIS B EPIDEMIOLOGY}

IMD is a rapidly progressing, life-threatening infection caused by Neisseria meningitidis. According to data extracted from the enhanced IMD surveillance system (10), between 154 and 229 cases of IMD were reported per year in Canada (2006 to 2011), with a mean annual incidence rate of 0.58 per 100,000 . Four serogroups (B, C, W-135 and Y) accounted for $91 \%$ of reported cases. The introduction of the meningococcal C conjugate vaccine across Canada from 2002 to 2005 led to reduced incidence of IMD due to serogroup C (MenC), with serogroup B (MenB) now being the most common cause of IMD. From 2006 to 2011, MenB accounted for $50 \%$ to $62 \%$ of all IMD cases in Canada. The incidence of MenB is highest in the pediatric population, with national age-specific incidence rates (cases per 100,000) reported to be $5.8,1.4$ and 0.7 , respectively, for children younger than one year of age; one to four years of age; and 15 to 19 years of age, in 2011 (6). Notably, $84 \%$ of all IMD cases in Canadian infants were caused by MenB (11).

In Ontario, the annual incidence of MenB from 2000 to 2010 ranged from 0.11 to 0.27 per 100,000 (12). Of key importance, the incidence of IMD due to MenC was 0.27 per 100,000 in 2001 , at the peak of the outbreak, and was 0.10 per 100,000 at the time of introducing the MenC conjugate vaccine in 2005 (Figure 2) (13). It should be emphasized that MenB incidence was higher than that of MenC in $2005(0.15$ per 100,000 ) and has remained above this level (ranging from 0.11 to 0.27 per 100,000 from 2005 to 2010) (12). The same trends have been observed nationally, with MenB incidence exceeding that of MenC every year between 2002 to 2009 (14). These incidence data, combined with the frequency of death and disabling sequelae, provide a strong rationale to extend IMD prevention by introducing routine immunizing programs to protect against serogroup $B$.

\section{RECOMMENDATIONS OF THE PEDIATRICIANS OF ONTARIO FOR IMMUNIZATION AND PREVENTION OF MENB}

Despite aggressive and timely treatment efforts, MenB can kill or cause serious life-long disabilities within $24 \mathrm{~h}$ of onset (15). Vaccination is, therefore, the best defense against this devastating disease. While MenA, MenC and quadrivalent (MenACWY) vaccines have been available for several years (16), the new $4 \mathrm{CMenB}$ vaccine was first licensed in 2013 (5,17-19), filling a final critical gap in IMD prevention. In Canada, the $4 \mathrm{CMenB}$ vaccine is approved for children and adolescents two months to 17 years of age (5). During the January 18 , 2014 meeting of the Pediatricians of Ontario, draft recommendations were proposed by panel speakers, and five key recommendations (R1 to R5) regarding immunization policy were put forth following discussion by all meeting participants, with a primary focus on $4 \mathrm{CMenB}$ vaccination for children.

\section{The Pediatricians of Ontario:}

Recommendation (R) 1: Support the routine use of the newly licensed $4 \mathrm{CMenB}$ vaccine for children;

R2: Recommend that Ontario funds the newly licensed 4CMenB vaccine as part of its public immunization program (ie, as a critical priority among other 'licensed but unfunded' vaccines) to ensure vaccine access for all Ontario families; 


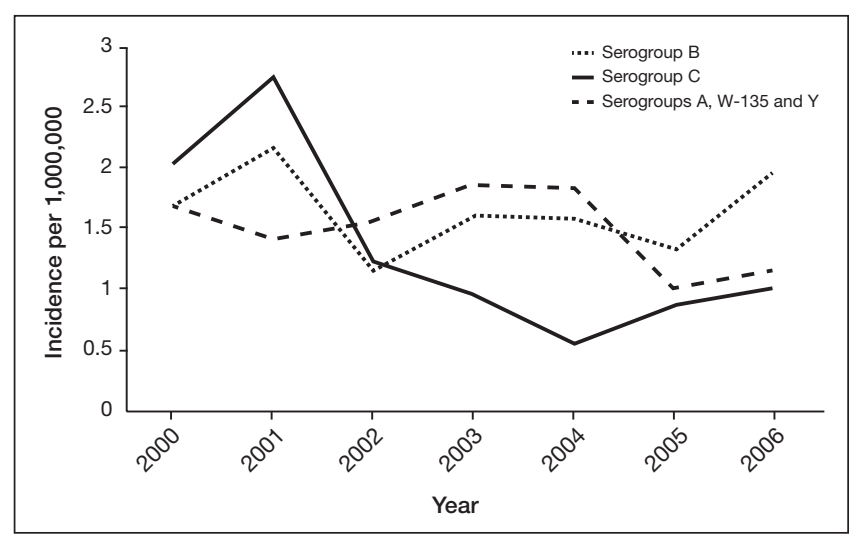

Figure 2) Annual incidence of invasive meningococcal disease according to serogroup in Ontario, 2000 to 2006

R3: Support public funding for other 'licensed but unfunded' vaccines, including vaccines targeting hepatitis $\mathrm{A}$ and $\mathrm{B}$ (administered together), human papillomavirus (HPV) for males and MenACWY for infants;

R4: Recommend ongoing review and alignment of legally mandated vaccines (as specified under the Immunization of School Pupils Act [ISPA]) with those recommended by NACI and with publicly funded vaccines and;

R5: Recommend that pediatricians secure increased membership on national (ie, NACI and/or Canadian Immunization Committee) and jurisdictional (ie, Provincial Infectious Disease Advisory Committee or Public Health Ontario) immunization advisory committees, to ensure direct contribution to key policy/funding decisions.

To evaluate the extent of agreement with these recommendations, a follow-up survey was conducted online to canvass all members of the Pediatricians of Ontario between April 1 (following the release of the NACI statement regarding the use of the $4 \mathrm{CMenB}$ vaccine [6]) and April 24, 2014. During the survey period, 120 responses were received, corresponding to a response rate of $10 \%$. While the response rate was low, respondents confirmed broad agreement with proposed recommendations (Table 1). Specifically, $>89 \%$ strongly agreed or agreed with all five recommendations, with $53 \%$ to $63 \%$ in strong agreement. These data are consistent with significant member interest in advocating for pediatric immunization, reinforcing our support for publicly funding of 4CMenB and other 'licensed but unfunded' vaccines.

\section{STATUS OF 4CMENB IMMUNIZATION}

\section{RECOMMENDATIONS AND PUBLIC PROGRAMS}

The provincial recommendations proposed by the Pediatricians of Ontario (R1 and R2) stand in contrast with current NACI recommendations, which state that, given the current available information regarding the burden of IMD in Canada, as well as the lack of evidence and range of uncertainty of underlying assumptions (particularly concerning the predicted level of strain susceptibility, duration of protection, impact on meningococcal carriage and herd immunity and potential adverse effects of vaccination at the population level), a recommendation for implementing a routine immunization program for MenB in Canada cannot be made at the present time (6). However, the vaccine may be considered (permissively) on an individual basis, for individuals $\geq 2$ months of age. The NACI recommendations also offer impractical guidance for vaccine use in the management of outbreaks and travel, ie, by advising that laboratory testing (which may be inaccessible) be conducted before vaccine administration.

Notably, the recommendations of the Pediatricians of Ontario are in alignment with current recommendations of the Joint Committee on Immunisation in the United Kingdom (20) and the Australian Technical Advisory Group on Immunisation in Australia (18), which recommend routine $4 \mathrm{CMenB}$ immunization of infants. The Pediatricians of Ontario position is also consistent with previously
TABLE 1

Pediatricians of Ontario member survey responses to recommendations

\begin{tabular}{lccccc}
\hline $\begin{array}{l}\text { Extent of } \\
\text { agreement/ } \\
\text { disagreement }\end{array}$ & $\mathbf{1}$ & $\mathbf{2}$ & $\mathbf{3}$ & $\mathbf{4}$ & $\mathbf{5}$ \\
\cline { 2 - 6 } & \multicolumn{6}{c}{ Recommendation } \\
\hline Strongly agree & $64(53.33)$ & $64(53.78)$ & $65(54.62)$ & $75(63.03)$ & $73(61.34)$ \\
Agree & $44(36.67)$ & $43(36.13)$ & $41(34.45)$ & $39(32.77)$ & $37(31.09)$ \\
Neutral & $7(5.83)$ & $7(5.88)$ & $9(7.56)$ & $5(4.2)$ & $8(6.72)$ \\
Disagree & $3(2.50)$ & $2(1.68)$ & $2(1.68)$ & $0(0)$ & $0(0)$ \\
Strongly disagree & $2(1.67)$ & $3(2.52)$ & $2(1.68)$ & $0(0)$ & $1(0.84)$ \\
Total respondents & $120(100)$ & $119(100)$ & $119(100)$ & $119(100)$ & $119(100)$ \\
\hline Data presented as $n(\%)$ & & & &
\end{tabular}

published NACI $(21,22)$ and Canadian Paediatric Society (23) statements, identifying the need to develop a MenB vaccine.

At the regional level in Canada, the Ministry of Health and Social Services of Quebec announced, in April 2014, its plan to fund a local, targeted 4CMenB vaccination campaign in the Saguenay-Lac-SaintJean region. The decision was made due to the high incidence of MenB infection in this region (24). The campaign, which ran from May 5, 2014, to December 31, 2014, represented the first Canadian $4 \mathrm{CMenB}$ vaccination program, and was also the most comprehensive program globally, because it encompasses all individuals two months to 20 years of age, and province-wide coverage of high-risk groups (25). In February 2015, a publicly funded MenB vaccination program was also implemented at Nova Scotia's Acadia University, in response to an institutional outbreak (two MenB cases), targeting all students and faculty/staff with certain medical conditions (26).

\section{PEDIATRICIANS OF ONTARIO OPINION - SUPPORTING 4CMENB VACCINATION}

Because the primary responsibility of frontline pediatricians is to protect individual children, the Pediatricians of Ontario presented arguments to support routine use (R1) and funding (R2) of the 4CMenB vaccine in Ontario. Given the periodic and sporadic nature of surges in incidence of group B meningococcus, we advocate for proactive prevention of MenB disease, rather than waiting for outbreaks, before implementing targeted or outbreak control strategies. The Pediatricians of Ontario position is consistent with past public health guidance regarding IMD vaccine recommendations. Our arguments address the burden of MenB disease, vaccine coverage, cost effectiveness (as primary concerns raised by policy-makers), as well as acceptability, and legal, political and ethical considerations related to $4 \mathrm{CMenB}$ vaccine introduction. In particular, we submit that currently available estimates are conservative in terms of describing MenB incidence and vaccine coverage of MenB strains, as well as the economic attractiveness of $4 \mathrm{CMenB}$ vaccination. By providing more accurate assessments, we aim to assist practitioners in communicating effectively with parents regarding MenB disease and $4 \mathrm{CMenB}$ immunization and, more broadly, to inform policy decision makers and help justify vaccine program implementation in Ontario.

\section{Technical limitations result in conservative estimation of MenB disease burden}

Although IMD caused by MenB is rare, currently available data inevitably underestimate actual MenB incidence, due to limitations in case ascertainment. Notably, laboratory confirmation is a necessary part of case reporting. Early treatment with antibiotics can limit the ability to detect $N$ meningitidis using culture methods alone, producing 'culturenegative' results. In addition, increased use of polymerase chain reaction (PCR) testing would increase identification of the causal serogroup by $30 \%$ to $50 \%$ (27). However, PCR testing was introduced only in 2009, and of the cases identified nationally and in Ontario, only $10 \%$ and $7 \%$ were confirmed by PCR, respectively $(10,13)$. While active surveillance systems, such as the Canadian Immunization 
Monitoring Program, ACTive (28) and the Toronto Invasive Bacterial Disease Network (29), offer improvements over passive surveillance (via notifiable disease reports), underdetection of MenB cases may still occur, due to the uncommon usage of PCR testing in Canada. Hence, in general, current incidence data for MenB are conservative.

\section{Predicted strain coverage by $4 \mathrm{CMenB}$ vaccine is conservative}

Although significant challenges have hindered the development of a vaccine against MenB disease due to the lack of an immunogenic capsule $(30,31)$, the ground-breaking reverse vaccinology approach has enabled identification of several subcapsular, surface-expressed protein antigens that are both highly conserved among MenB strains and able to induce bactericidal antibodies (32). This research laid the foundation for developing the current $4 \mathrm{CMenB}$ vaccine, comprised of three purified recombinant protein antigens, along with an outer membrane vesicle component (containing the PorA protein subtype 1.4) (33). The immunogenicity, safety and tolerability of this newly approved $4 \mathrm{CMenB}$ vaccine has been demonstrated in clinical trials in $>8000$ subjects to date (27). Specifically, the vaccine has been shown to elicit a strong immune response in infants, toddlers and adolescents (34-36) based on the serum bactericidal assay (SBA), an established correlate of protection for MenB (37).

The $4 \mathrm{CMenB}$ vaccine will not be expected to provide protection against all circulating MenB strains, however, because not all strains express antigens contained in the vaccine. Hence, evaluation of strain coverage is necessary (18). To estimate potential coverage of the vaccine, a new assay has been developed, referred to as the Meningococcal Antigen Typing System (MATS) (38). Using small sera volumes, the high throughput-MATS assay can quantify and characterize the protein concentration of vaccine antigens expressed on MenB strains, and will estimate the proportion of circulating strains that may be expected to be killed by antibodies induced by the $4 \mathrm{CMenB}$ vaccine (27). For MATS calculations, individual strain killing is predicted when at least one recombinant protein antigen concentration equals or exceeds its validated positive bactericidal threshold value (or the presence of the dominant PorA 1.4 variant is detected) (33), thus making the strain susceptible to killing by vaccine-induced antibodies. In essence, MATS testing can assess the degree to which the vaccine antigens match the surface proteins of a diverse panel of disease-causing MenB strains. This approach has been used to assess vaccine coverage of strains representing specific geographical areas (39).

In Canada, the potential of the $4 \mathrm{CMenB}$ vaccine to cover circulating strains from 2006 to 2009 has been tested; 157 isolates were recently characterized using MATS. The predicted strain coverage of the $4 \mathrm{CMenB}$ vaccine was $66 \%$ (40). However, MATS estimates are believed to be conservative. A recent study from the United Kingdom tested a representative sample from all MenB disease isolates collected in England and Wales in 2007 to 2008 against pooled sera from infant and adolescent vaccines, using both human SBA and MATS assays (33). While MATS predictions and human SBA results were significantly associated $(\mathrm{P}=0.022)$, MATS predicted $4 \mathrm{CMenB}$ vaccine coverage of $70 \%$, whereas human SBA results indicated $88 \%$ killing. Because fully $66 \%$ of strains predicted 'not covered' by MATS were killed in the human SBA assay (and thus represented false negatives by MATS), it was suggested that possible bactericidal synergy may occur for antibodies raised against multiple antigens, even when MATS results indicate that individual antigen levels fall below their respective positive bacterial thresholds. In addition, in the Canadian study, it was also suggested that because expression of one of the protein antigens is repressed in in vitro (but not in in vivo) conditions, MATS may underestimate the contribution of that antigen to vaccine strain coverage (40). Overall, researchers have concurred that MATS is a conservative predictor of $4 \mathrm{CMenB}$ strain coverage $(27,33,38,40)$.

It should be noted that because all four protein antigens of the $4 \mathrm{CMenB}$ vaccine may be present in the outer membrane of non- $\mathrm{B}$ serogroups, antibodies induced by the vaccine may also have bactericidal activity against other serotypes of IMD (35). Hence, while the vaccine is anticipated to outperform the MATS estimate of protection against $66 \%$ of MenB strains (as argued above), the vaccine's effectiveness may also extend to non-B strains $(8,15)$. In this context, the innovative research that has led to the revolutionary development of the $4 \mathrm{CMenB}$ vaccine may indeed be considered to be the first step toward universal strain coverage across all IMD serogroups (41).

\section{Current economic assessments underestimate the attractiveness of 4CMenB immunization}

It is critically important that the assessment of vaccine cost effectiveness be evaluated in accordance with current best practice guidelines for the economic evaluation of communicable disease control interventions (42). For $4 \mathrm{CMenB}$ vaccination, cost-effectiveness models (eg, estimating cost per quality-adjusted life year [QALY] [cost/QALY] and number needed to vaccinate $[\mathrm{NNV}]$ ) should assume dynamic disease transmission, with direct vaccine impact on vaccinated individuals, as well as indirect impact on unvaccinated individuals. First, the use of an early outer membrane vesicle vaccine targeting $\mathrm{MenB}$, a single component preparation of the current $4 \mathrm{CMenB}$ vaccine, has led to successful control of an epidemic of group B meningococcal disease in New Zealand $(43,44)$. Second, herd immunity effects associated with indirect protection have been profoundly underestimated before the widespread utilization of other recently introduced vaccines, including Haemophilus influenzae type b vaccine (45); conjugate pneumococcal vaccines $(46)$; HPV vaccine $(47,48)$; rotavirus vaccines (49); and group C conjugate meningococcal vaccine (13), also strengthening the rationale for dynamic cost-effectiveness modelling approaches for $4 \mathrm{CMenB}$ immunization.

Moreover, while the impact of $4 \mathrm{CMenB}$ vaccine on MenB carriage dynamics is not yet known, there is reasonable expectation of vaccine efficacy against meningococcal $\mathrm{B}$ carriage rates (and hence broader herd immunity impact), based on available literature to date $(20,50)$. Indirect effects will be evaluated in the near term in global surveillance and phase IV studies. In the interim, however, as post-implementation phase data are awaited, available models for $4 \mathrm{CMenB}$ vaccination have unfortunately focused primarily on static analyses (including Markov models and decision trees), assuming only direct protection of vaccines, to calculate cost/QALY (6) and NNV $(8,12)$. As a result, cost/QALY and NNV results from 'static risk' modelling are likely misestimated. Notably, for static models estimating NNV, the magnitude of distortion is projected to be greatest with partially effective vaccines and those against diseases with lower reproductive numbers, such as meningococcal infection, in which even modest reductions in carriage may lead to collapse of disease in a population (51). In general, although static risk estimates have been used by policy makers in the economic evaluation of routine $4 \mathrm{CMenB}$ immunization, vaccine benefits are likely to extend beyond those vaccinated. Hence, there is need for significant caution in accepting conclusions from static modelling studies that suggest 4CMenB immunization programs may not be cost effective.

Given the wide range of clinical sequelae that can result from IMD, including amputation, cognitive delay, requirement for multiple corrective surgeries and future loss of productivity $(52,53)$, it is important that the full range of sequelae be included in economic evaluations of vaccination. Failure to do so will result in analyses that are biased against vaccine economic attractiveness.

Another key concept to consider is that cost effectiveness of immunization needs to be estimated against the costs and consequences of nonadoption of routine $4 \mathrm{CMenB}$ immunization programs (or by targeting selective at-risk populations), which may culminate in the need to implement reactive outbreak control strategies. Because MenB is highly unpredictable, outbreak control can be extremely disruptive from a public health standpoint, requiring extensive resources to manage, ie, in terms of organizing vaccine supply and delivery, setting up local clinics, and swiftly developing effective educational programs, as reported during the 2013 to 2014 United States college outbreak campaigns (54). Significant expenses will inevitably be incurred in treating additional patients who are infected before clinic mobilization, and to provide prophylactic antimicrobials and vaccines to exposed contacts (55). 
Finally, it must be emphasized that cost effectiveness is one of several drivers of the decision to adopt a novel vaccine (56); ethical, political, and disease dynamic considerations are also important. Other vaccines, even against IMD, have been funded in Ontario, despite having high costs per health outcome; most notably, the MenC immunization program was implemented for public health reasons beyond merely cost analyses, and is now considered to be highly effective - in fact, a public health triumph. In essence, society has accepted vaccination against MenC because prevention of such a rare, but serious disease is deemed a worthwhile public health goal (57).

\section{Public funding is critical for vaccine acceptance}

Parental acceptance of meningococcal vaccines is very high in Canada (58). To assess parental acceptability of $4 \mathrm{CMenB}$ vaccine, a national study was conducted with parents presenting infants two to six months of age for vaccination (59). Parents were given a short description of meningitis and the new vaccine, and then were surveyed as to their intention to vaccinate. Results demonstrated that the majority $(84.7 \%)$ of parents intended to vaccinate their infants with MenB vaccine when it was free of charge as a publicly funded vaccine. Intention to vaccinate decreased to $63 \%$ (at $\$ 50$ per dose) and $46.8 \%$ (at $\$ 100$ per dose). Yearly income was explanatory only at the extreme income levels $(>\$ 80,000$ versus $<\$ 40,000)$. To explore this heuristic further, parents were surveyed regarding their beliefs about public funding. Specifically, absence of public funding had a substantial impact regarding beliefs about MenB vaccine: $82 \%$ of parents agreed that if MenB 'was really an important threat to infants'; if the vaccine was 'really effective ( $81 \%)$; and if the vaccine was 'safe' (74\%), then Public Health would fund the MenB vaccine. Hence, public funding adds validity to the importance and value of immunization. In contrast, unfunded vaccines may be perceived as targeting diseases that are less severe, may be viewed as unsafe and are particularly vulnerable to anti-vaccination sentiment (1). Overall, public funding is believed necessary to convey a deep societal commitment to the extraordinary value of childhood immunization in Canada (60), and is anticipated to be a critical factor in influencing acceptance of the $4 \mathrm{CMenB}$ vaccine.

\section{Legal issues: ISPA and Canadian Medical Protective Association} regulations support immunization against IMD

Recent amendments have been made to Ontario's ISPA to strengthen the protection of school children from vaccine-preventable diseases. Effective July 1, 2014, meningococcal disease, pertussis and varicella have been added as designated diseases requiring proof of immunization for school attendance (or parental request for exemption) (61). The Pediatricians of Ontario support this new ISPA legislation, which clearly demonstrates the Ontario government's commitment to meningitis prevention through vaccination. Specifically, the amendment requires immunization with meningococcal conjugate- $\mathrm{C}$ vaccine (no earlier than one year of age), and meningococcal conjugate-ACWY at 12 years of age (grade 7 or above) (62). While 4CMenB immunization has not yet been explicitly legislated, it should be noted that the ISPA was amended in October 2013, before vaccine licensure in December 2013.

In general, the recent ISPA amendments represent tangible progress in terms of ongoing review and alignment of legally mandated vaccines with those routinely recommended by NACI and funded in Ontario (as called for in R4). Interestingly, the Pediatricians of Ontario survey results (Table 1) indicate that $\mathrm{R} 4$ had the highest percentage $(>95 \%)$ of member agreement (ie, 63\% strongly agreed; 33\% agreed), versus other recommendations ranging from $89 \%$ to $92 \%$ agreement, suggesting that $\mathrm{R} 4$ resonated most deeply with Ontario pediatricians, likely due to challenges in managing questions regarding vaccine requirements, and the accompanying paperwork for school expulsion and re-entry. Furthermore, because the Pediatricians of Ontario position is that the $4 \mathrm{CMenB}$ vaccine should be routinely recommended (R1) and publicly funded (R2), we also urge that the vaccine should be added to the list of immunizations required for school entry (as part of a continuous review and amendment process, R4), to extend protection against future outbreaks of meningococcal disease.

Under current ISPA regulation, parents are likely to be confused about which meningococcal vaccines (ie, against specific serogroups) are included. Moreover, given that the $4 \mathrm{CMenB}$ vaccine targets the most prevalent IMD serogroup in Ontario, the rationale for 4CMenB's exclusion from current ISPA regulation will be difficult to explain and, potentially, to legally defend. In addition to recommending that 4CMenB vaccination be legislated, the Pediatricians of Ontario also advocate for public funding of other vaccines in Ontario (R3), including those against hepatitis A and B (administered together); HPV for males; and MenACWY for infants, and similarily, for the inclusion of these immunizations on the list designated under the ISPA.

Another key legal issue is that the Canadian Medical Protective Assoiciation (CMPA) (63) has advised physicians on their obligation to inform parents about new vaccines that are licensed but not publicly funded. If the issue were to come before the courts, 'standard of care' is determined by factors such as: medical publications, common practice of other physicians, and recommendations from governments or professional bodies. CMPA specifies that if a risk is rare, but the potential outcome is severe, there is an obligation to discuss this with patients (63). Hence, a routine recommendation for the $4 \mathrm{CMenB}$ vaccine (as called for by the Pediatricians of Ontario; R1) would satisfy one of these conditions. The presence of Ontario legislation mandating vaccination against less prevalent serogroups of IMD may be argued to be another (62). Previous NACI statements identifying the need for a MenB vaccine may also weigh as relevant evidence $(21,22)$. Therefore, even while the vaccine is not yet included in routine vaccination programs, it remains the responsibility of pediatricians, general practitioners and public health officials to educate and advise parents about the vaccine, enabling them to make informed decisions regarding immunization of their children (11). Pediatricians in particular are in a position to recommend $4 \mathrm{CMenB}$ vaccination, because infants are at the highest risk.

\section{Political considerations anticipated to be paramount}

Given the unpredictability and high media profile surrounding MenB disease, political issues are anticipated to be paramount in determining the priority of $4 \mathrm{CMenB}$ vaccine funding in jurisdictional immunization programs. Notably, the WHO has recently issued a guidance document outlining key principles for introducing a new vaccine into publicly funded programs (64). This report indicates that certain diseases, including meningitis (and dengue), may not cause high mortality, but because of the fear they engender among the public and clinicians (due to difficulties with diagnosis and inadequate treatments), as well as the great disruptions caused by outbreaks, such diseases are often ranked as top priorities by political leaders, the medical community and the public. In Canada, there is strong public perception that IMD prevention is a priority. It will be difficult for politicians to resist the plea to introduce $4 \mathrm{CMenB}$ vaccine programs to prevent this disease in children and adolescents, especially when vaccine programs already exist for less prevalent serogroups. Indeed, powerful public appeal processes are already in place, as evidenced by the formation of politically active patient advocacy groups, comprised mainly of families affected by meningitis $(65,66)$.

\section{Ethical considerations raised}

A number of ethical questions must be raised in the context of introducing the new $4 \mathrm{CMenB}$ vaccine. First and foremost, given that IMD is not limited to serogroups $\mathrm{A}, \mathrm{C}, \mathrm{W}$ and $\mathrm{Y}$, for which vaccines are currently available (and funded across many Canadian jurisdictions) (67), is it ethically responsible to not extend protection by implementing routine immunization programs for a vaccine targeting MenB, which is the most common cause of IMD? Second, if a sophisticated breakthrough vaccine against devastating MenB disease has been developed and gained approval as the new standard of care in Canada, does it 
not follow from an ethics perspective that appropriate immunization programs should be implemented and funded, to avoid future morbidity and mortality in the pediatric population? Finally, from a public health equity standpoint, if access to funded $4 \mathrm{CMenB}$ immunization is denied, is it fair to offer vaccination only to wealthy Canadians?

\section{CONCLUSION}

The arguments presented herein are intended to assist practicing clinicians in advocating the benefits of $4 \mathrm{CMenB}$ vaccination, facilitating recommendations for individual children. However, in addressing the broader public health perspective, the primary intent of the present article is to inform policy and funding decisions, and provide counterbalance to current NACI opinion, surrounding 4CMenB immunization, particularly in targeting Ontario's immunization advisory bodies (eg, Provincial Infectious Disease Advisory Committee/Public Health Ontario). In putting forth R5, we also recommend that pediatricians should seek increased opportunities for direct participation on national (NACI) and jurisdictional immunization advisory committees, to contribute the pediatricians' view as a critical voice in formulating policies regarding IMD immunization and public funding programs.

Ultimately, the Pediatricians of Ontario position underscores the urgent medical need for MenB prevention in reducing childhood mortality and morbidity; we advocate that the new $4 \mathrm{CMenB}$ vaccine should be included in Ontario's routine immunization schedule. While we emphasize that the decision to introduce the $4 \mathrm{CMenB}$ vaccine should be based on up-to-date, accurate estimates (primarily including local disease epidemiology, vaccine strain coverage and cost effectiveness), we submit that assumptions and/or estimates used in these areas have been conservative in evaluations to date, thus underestimating the true value of $4 \mathrm{CMenB}$ immunization. Our view is that public funding for $4 \mathrm{CMenB}$ immunization is justified, particularly because routine recommendations and funding are currently in place for meningococcal serogroups that cause significantly less disease in Canada. We propose that Ontario (and other Canadian jurisdictions) must continue to invest in childhood immunization, based not only on past successes, as observed with the MenC vaccine, but also to minimize future disease burden by extending immunization coverage as the most efficient strategy for IMD prevention. Overall, within the context of the rapidly advancing Canadian vaccine landscape, the Pediatricians of Ontario aim to spark discussion and build consensus, particularly regarding funding for vaccines targeting IMD, across a wide audience of policy-makers in the fields of pediatrics, infectious disease, public health and family medicine.

GRANT FUNDING: The January 18, 2014 meeting and publication were funded by an American Academy of Pediatrics Educational Grant, Ontario Chapter (Pediatricians Alliance of Ontario), supported by Novartis.

ACKNOWLEDGEMENTS: From the Educational Grant described above, Dr Cutcliffe received funding for medical writing and manuscript preparation, and Dr Dobson and Dr Gold received honoraria for their presentations at the January 18, 2014 meeting of the Pediatrics Section of the Ontario Medical Association/Pediatricians Alliance of Ontario. The authors gratefully thank Robyn Neville-Kett, Executive Director, Pediatrics Section of the Ontario Medical Association/Pediatricians Alliance of Ontario, for overseeing the grant application process, disbursement of all grant funds, and for her assistance with compiling survey data. They also thank Maria Major, Medical Science Liaison - Vaccines, Novartis Pharmaceuticals Canada Inc, for her contribution to the literature search, including key epidemiology data and figures, in preparing the manuscript.

12. Dang V, Jamieson F, Wilson S, et al. Epidemiology of serogroup B invasive meningococcal disease in Ontario, Canada, 2000 to 2010. BMC Infect Dis 2012;12:202.

13. Kinlin LM, Jamieson F, Brown EM, et al. Rapid identification of herd effects with the introduction of serogroup $\mathrm{C}$ meningococcal conjugate vaccine in Ontario, Canada, 2000-2006. Vaccine 2009;27:1735-40.

14. Bettinger JA, Scheifele DW, Le Saux N, et al. The disease burden of invasive meningococcal serogroup B disease in Canada. Pediatr Infect Dis J 2013;32:e20-e25.

15. World Health Organization. Bacterial Meningitis. <http://apps.who. int/nuvi/meningitis/en/> (Accessed February 27, 2015).

16. World Health Organization. Meningococcal Meningitis. Fact sheet 141. November 2012. <www.who.int/mediacentre/factsheets/fs141/ en/index.html> (Accessed February 27, 2015).

17. Joint Committee on Immunisation. JCVI interim position statement on use of Bexsero® meningococcal B vaccine in the UK. July 2013. <www.gov.uk/government/uploads/system/uploads/ attachment_data/file/224896/JCVI_interim_statement_on_ meningococcal_B_vaccination_for_web.pdf $>$ (Accessed February 27, 2015).

18. Australian Technical Advisory Group on Immunisation (ATAGI) Statement. Advice for immunisation providers regarding the use of Bexsero ${ }^{\circledR}$ - a recombinant multicomponent meningococcal $B$ vaccine (4CMenB). March 2014. <www.immunise.health.gov.au/ internet/immunise/publishing.nsf/Content/atagi-advice-bexsero> (Accessed February 27, 2015).

19. FDA News Release. FDA approves a second vaccine to prevent serogroup B meningococcal disease. Jan. 23, 2015. $<$ www.fda.gov/NewsEvents/Newsroom/PressAnnouncements/ ucm431370.htm> (Accessed February 27, 2015).

20. Joint Committee on Immunisation. JCVI position statement on use of Bexsero® meningococcal B vaccine in the UK. March 2014. <www.gov.uk/government/uploads/system/uploads/attachment_data/ file/294245/JCVI_Statement_on_MenB.pdf > (Accessed February 27, 2015).

11. Sadarangani M, Bettinger JA, Scheifele DW. How best to describe the risk of meningococcal B infection? Paediatr Child Health 2013;18:543. 
21. National Advisory Committee on Immunization (NACI). Statement on recommended use of meningococcal vaccines. CCDR 2001;27(ACS-6):2-36.

22. National Advisory Committee on Immunization (NACI). Update on the Invasive Meningococcal Disease and Meningococcal Vaccine Conjugate Recommendations. CCDR April 2009;35(ACS-3):1-40.

23. Salvadori M, Bortolussi R. Meningococcal vaccines in Canada: An update. Paediatr Child Health 2011;16:485.

24. Agence de la santé et des services sociaux du Saguenay-Lac-SaintJean. Communiqué. Campagne de vaccination ciblée contre le méningocoque dans la région du Saguenay-Lac-Saint-Jean. April 22, 2014. <http://santesaglac.com/medias/Vaccination_mening_B/ Communique-Meningo-Saglac-22-avril-16h_FINAL.pdf> (Accessed February 27, 2015).

25. Agence de la santé et des services sociaux Québec. Targeted Meningococcal Serogroup B Vaccination Campaign in the Saguenay-Lac-Saint-Jean Region. April 2014. <www.msss.gouv.qc. ca/sujets/santepub/vaccination/index.php?accueil_en> (Accessed February 27, 2015).

26. Acadia University students line up for meningitis vaccinations. CBC News. February 18, 2015. <www.cbc.ca/news/canada/novascotia/acadia-university-students-line-up-for-meningitisvaccinations-1.2961246> (Accessed February 27, 2015).

27. Major M, Moss S, Gold R. From genes to vaccine: A breakthrough in the prevention of meningococcal group B disease. Paediatr Child Health 2011;16:e61.

28. IMPACT. Canadian Immunization Monitoring Program, ACTive. Surveillance. What is IMPACT? <www.cps.ca/en/impact> (Accessed February 27, 2015).

29. Toronto Invasive Bacterial Diseases Network (TIBDN). Surveillance for invasive infection due to Neisseria meningitidis. $<$ http://tibdn.ca/studies/surveillance-meningitidis $>$ (Accessed February 27, 2015).

30. Finne J, Leinonen M, Mäkelä PH. Antigenic similarities between brain components and bacteria causing meningitis: Implications for vaccine development and pathogenesis. Lancet 1983;322:355-7.

31. Bai X, Borrow R. Genetic shifts of Neisseria meningitidis serogroup B antigens and the quest for a broadly cross-protective vaccine. Expert Rev Vaccines 2010;9:1203-17.

32. Rappuoli R. Reverse vaccinology. Curr Opin Microbiol 2000;3:445-50.

33. Frosi G, Biolchi A, Sapio ML, et al. Bactericidal antibody against a representative epidemiological meningococcal serogroup $B$ panel confirms that MATS underestimates $4 \mathrm{CMenB}$ vaccine strain coverage. Vaccine 2013;31:4968-74. <www.sciencedirect.com/ science/article/pii/S0264410X13010906> (Accessed February 27, 2015).

34. Gossger N, Snape MD, Yu LM, et al. Immunogenicity and tolerability of recombinant serogroup $\mathrm{B}$ meningococcal vaccine administered with or without routine infant vaccinations according to different immunization schedules: A randomized controlled trial. JAMA 2012;307:573-82.

35. Vesikari T, Esposito S, Prymula R, al. Immunogenicity and safety of an investigational multicomponent, recombinant, meningococcal serogroup B vaccine (4CMenB) administered concomitantly with routine infant and child vaccinations: Results of two randomised trials. Lancet 2013;381:825-35.

36. Santolaya ME, O'Ryan ML, Valenzuela MT, et al. Immunogenicity and tolerability of a multicomponent meningococcal serogroup B (4CMenB) vaccine in healthy adolescents in Chile: A phase $2 \mathrm{~b} / 3$ randomised, observer-blind, placebo-controlled study. Lancet 2012;379:617-24.

37. Frasch CE, Borrow R, Donnelly J. Bactericidal antibody is the immunologic surrogate of protection against meningococcal disease. Vaccine 2009;27(Suppl 2):B112-6.

38. Donnelly J, Medini D, Boccadifuoco G, et al. Qualitative and quantitative assessment of meningococcal antigens to evaluate the potential strain coverage of protein-based vaccines. Proc Natl Acad Sci USA 2010;107:19490-5.

39. Australian Government. Department of Health. Therapeutic Goods Administration. AusPAR Attachment 2. Extract from the Clinical Evaluation Report for Multi-Component Meningococcal B vaccine. May 3, 2013.
40. Bettinger JA, Scheifele DW, Halperin SA, et al. Diversity of Canadian meningococcal serogroup $\mathrm{B}$ isolates and estimated coverage by an investigational meningococcal serogroup $B$ vaccine (4CMenB). Vaccine 2013;32:124-30.

41. Rappuoli R. The challenge of developing universal vaccines. F1000 Med Rep 2011;3:16.

42. Pitman R, Fisman D, Zaric GS, et al. Dynamic transmission modeling: A report of the ISPOR-SMDM modeling good research practices task force-5. Value Health 2012;15:828-34. <www.ispor. org/workpaper/modeling_methods/dynamic_transmission_ modeling-5.pdf $>$ (Accessed February 27, 2015).

43. Delbos V, Lemée L, Bénichou J, et al. Impact of MenBvac, an outer membrane vesicle (OMV) vaccine, on the meningococcal carriage. Vaccine 2013;31:4416-20.

44. Holmes J, Martin D, Ramsay C, Ypma E, Oster P. Combined administration of serogroup $B$ meningococcal vaccine and conjugated serogroup $\mathrm{C}$ meningococcal vaccine is safe and immunogenic in college students. Epidemiol Infect 2008;136:790-9.

45. Schuchat A, Messonnier NR. From pandemic suspect to the postvaccine era: The Haemophilus influenzae story. Clin Infect Dis 2007;44:817-9

46. Kellner JD, Scheifele D, Vanderkooi OG, MacDonald J, Church DL, Tyrrell GJ. Effects of routine infant vaccination with the 7-valent pneumococcal conjugate vaccine on nasopharyngeal colonization with Streptococcus pneumoniae in children in Calgary, Canada. Pediatr Infect Dis J 2008;27:526-32.

47. Fairley CK, Hocking JS, Gurrin LC, Chen MY, Donovan B, Bradshaw C. Rapid decline in presentations of genital warts after the implementation of a national quadrivalent human papillomavirus vaccination programme for young women. Sex Transm Infect 2009;85:499-502.

48. Ali H, Donovan B, Wand H, et al. Genital warts in young Australians five years into national human papillomavirus vaccination programme: National surveillance data. BMJ 2013;346.

49. Glass RI, Patel M, Parashar U. Lessons from the US rotavirus vaccination program. JAMA 2011;306:1701-2.

50. Read R, Baxter D, Chadwick D, et al. Impact of quadrivalent conjugate (MenACWY-CRM) and serogroup B (4CMenB) meningococcal vaccines on meningococcal carriage in English university students (Abst). Meningitis and septicemia in children and adults 2013; London, England. November 2013.

51. Tuite AR, Fisman DN. Number-needed-to-vaccinate calculations: Fallacies associated with exclusion of transmission. Vaccine 2013;31:973-8. <http://dx.doi.org/10.1016/j.vaccine.2012.11.097> (Accessed February 27, 2015).

52. Sanchez IR, Meltzer MI, Shepard C, et al. Economics of an adolescent meningococcal conjugate vaccination catch-up campaign in the United States. Clin Infect Dis 2008;46:1-13.

53. Shepard CW, Ortega-Sanchez IR, Scott RD, Rosenstein NE, the ABCs Team. Cost-effectiveness of conjugate meningococcal vaccination strategies in the United States. Pediatrics 2005;115:1220-32.

54. Centers for Disease Control and Prevention. Serogroup B Meningococcal Vaccine and Outbreaks. <www.cdc.gov/ meningococcal/outbreaks/vaccine-serogroupB.html> (Accessed February 27, 2015).

55. Ontario Ministry of Health. Infectious Diseases Protocol. Appendix A: Disease-Specific Chapters. Chapter: Meningococcal disease, invasive. Revised January 2014. <www.health.gov.on.ca/en/ pro/programs/publichealth/oph_standards/docs/meningococcal_ chapter.pdf $>$ (Accessed February 27, 2015).

56. Erickson L, De Wals P, Farand L. An analytical framework for immunization programs in Canada. Vaccine 2005;23:2470-6.

57. Stanley M. Perspective: Vaccinate boys too. Nature 2012;488:S10.

58. Public Health Agency of Canada. Survey of Parents on Key Issues Related to Immunization. EKOS Research Associates Inc. September 2011. <http://resources.cpha.ca/immunize.ca/data/1792e.pdf> (Accessed February 27, 2015).

59. Fisher W, Bettinger J, Gilca V, et al. Understanding the impact of approved but unfunded vaccine status on parental acceptance of a novel meningococcal sergroup B vaccine for infants (Abst 0351). 32nd Meeting of the European Society for Paediatric Infectious Diseases (ESPID); Dublin, Ireland. May 8, 2014. 
60. Scheifele DW, Halperin SA, Bettinger JA. Childhood immunization rates in Canada are too low: UNICEF. Pediatr Child Health 2014;19:237-8.

61. Toronto Public Health Communique. May 2014. Issue 32. $<$ http://www1.toronto.ca/City\%200f\%20Toronto/Toronto\%20 Public\%20Health/Health\%20Professionals/Files/pdf/C/ CommuniqueMay2014Web.pdf > CommuniqueMay2014Web.pdf $>$ (Accessed February 27, 2015).

62. Government of Ontario. Immunization of School Pupils Act. R.R.O. 1990. REGULATION 645. <www.e-laws.gov.on.ca/html/ regs/english/elaws_regs_900645_e.htm> (Accessed February 27, 2015).

63. Canadian Medical Protective Association (CMPA). January 2009 (IS0887-E). New vaccines - What are your obligations? An article for physicians by physicians. <www.cmpa-acpm.ca/safety/-/asset_ publisher/N6oEDMrzRbCC/content/new-vaccines-what-are-yourobligations $>$ (Accessed February 27, 2015).
64. World Health Organization. Principles and considerations for adding a vaccine to a national immunization programme - from decision to implementation and monitoring. April 2014. $<$ www.who.int/immunization/documents/general/ ISBN_978_92_4_15068_92/en/> (Accessed February 27, 2015).

65. Meningitis Research Foundation of Canada. <www.meningitis.ca/ en/Home.aspx> (Accessed February 27, 2015).

66. Meningitis Relief. <www.meningitisrelief.com/home.html> (Accessed February 27, 2015).

67. National Advisory Committee on Immunization (NACI). Update on the use of quadrivalent conjugate meningococcal vaccines. CCDR. January 2013;39(ACS-1):1-40. <www.phac-aspc.gc.ca/ publicat/ccdr-rmtc/13vol39/acs-dcc-1/index-eng.php> (Accessed February 27, 2015). 


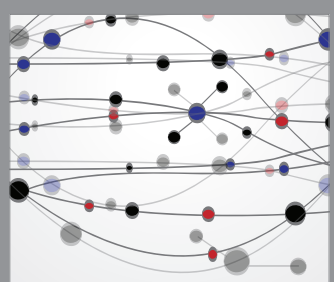

The Scientific World Journal
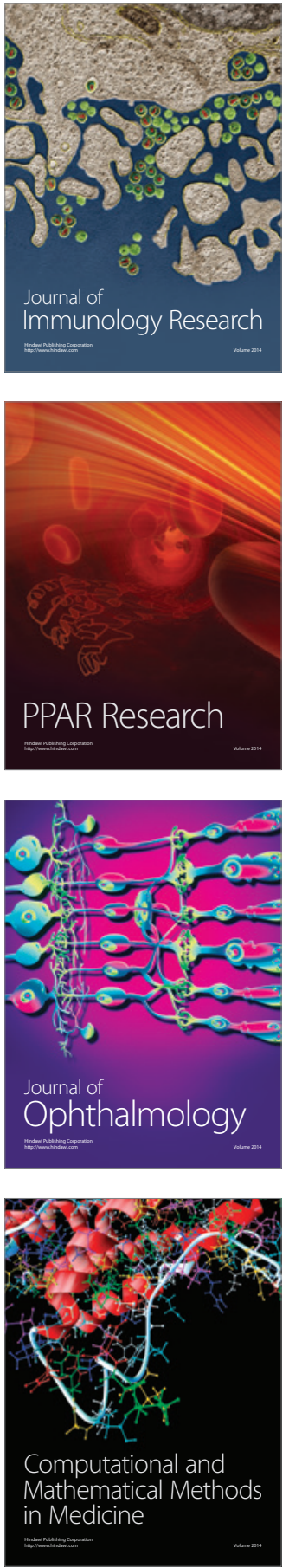

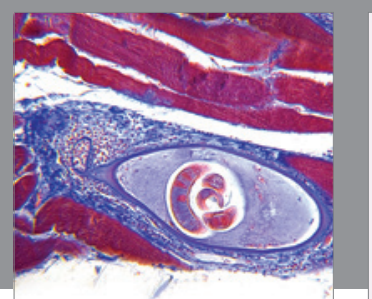

Gastroenterology Research and Practice

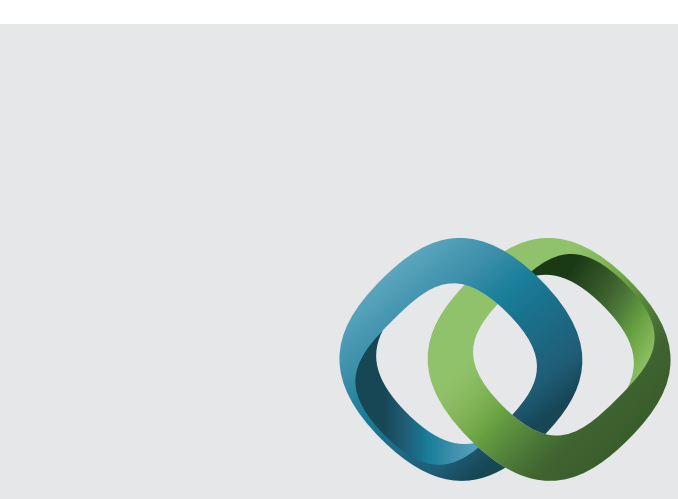

\section{Hindawi}

Submit your manuscripts at

http://www.hindawi.com
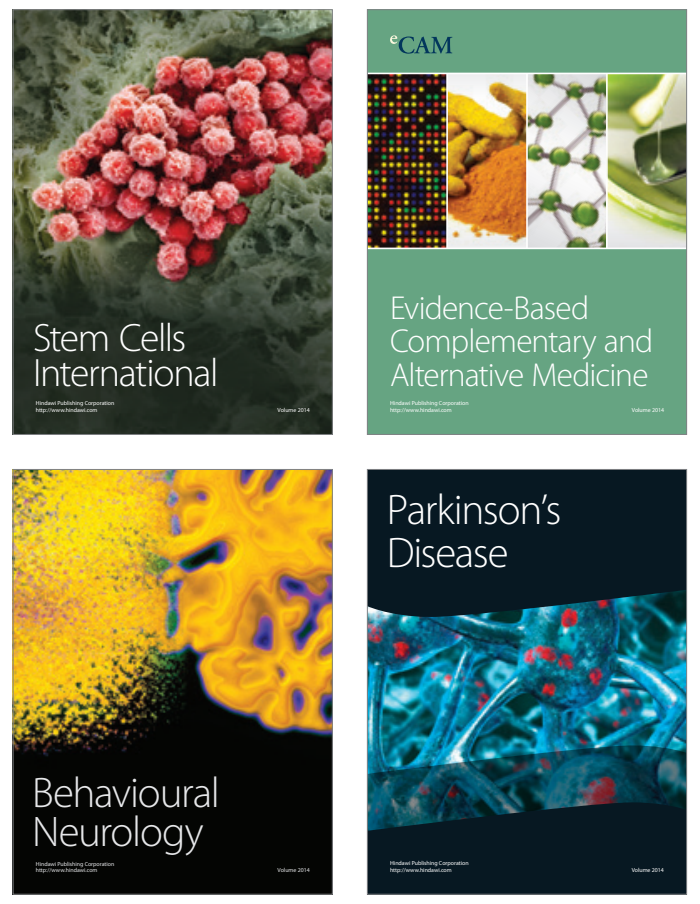
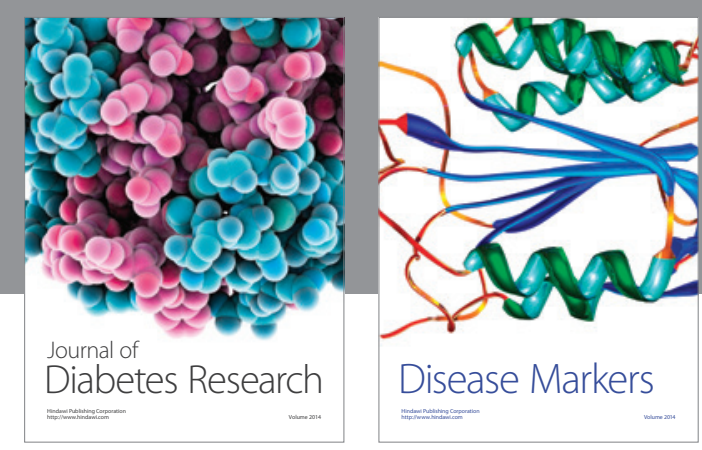

Disease Markers
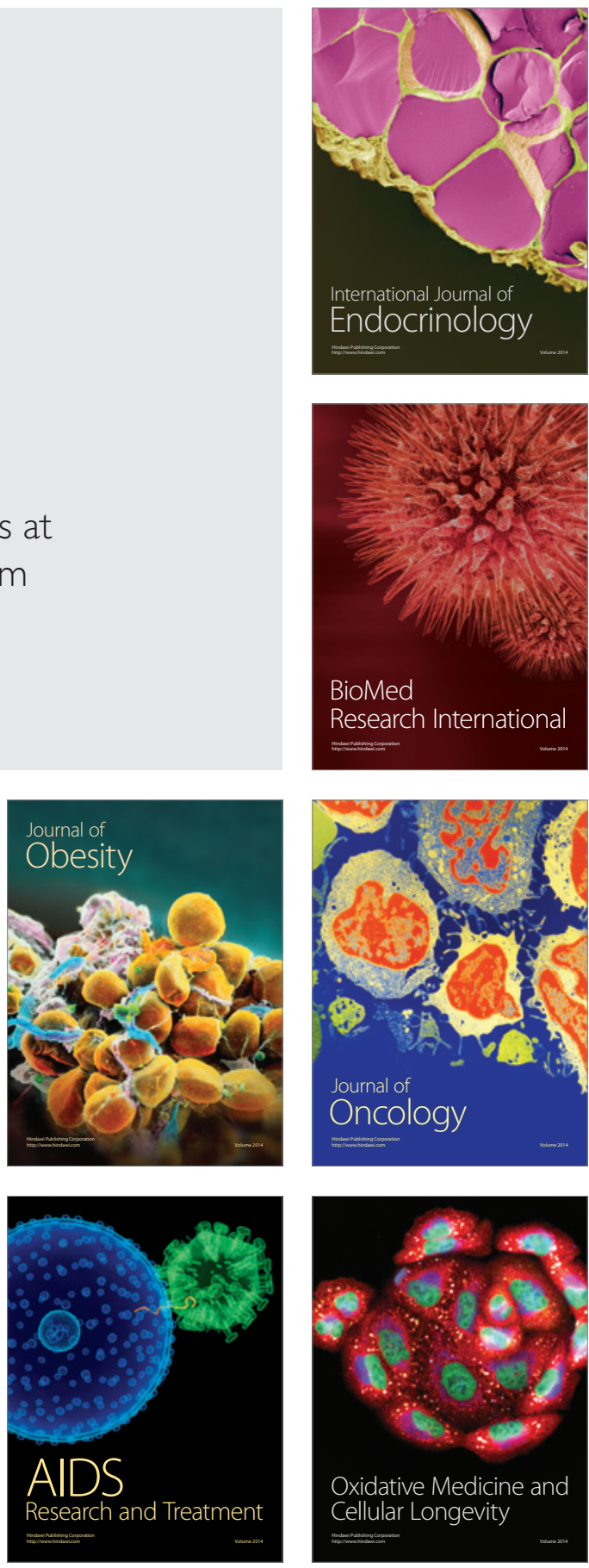